\title{
Histone deacetylases (HDACs) in XPC gene silencing and bladder cancer
}

\author{
Xiaoxin S Xu' ${ }^{1}$, Le Wang ${ }^{1}$, Judith Abrams ${ }^{2}$ and Gan Wang ${ }^{1 *}$
}

\begin{abstract}
Bladder cancer is one of the most common malignancies and causes hundreds of thousands of deaths worldwide each year. Bladder cancer is strongly associated with exposure to environmental carcinogens. It is believed that DNA damage generated by environmental carcinogens and their metabolites causes development of bladder cancer. Nucleotide excision repair (NER) is the major DNA repair pathway for repairing bulk DNA damage generated by most environmental carcinogens, and XPC is a DNA damage recognition protein required for initiation of the NER process. Recent studies demonstrate reduced levels of XPC protein in tumors for a majority of bladder cancer patients. In this work we investigated the role of histone deacetylases (HDACs) in XPC gene silencing and bladder cancer development. The results of our HDAC inhibition study revealed that the treatment of HTB4 and HTB9 bladder cancer cells with the HDAC inhibitor valproic acid (VPA) caused an increase in transcription of the XPC gene in these cells. The results of our chromatin immunoprecipitation (ChIP) studies indicated that the VPA treatment caused increased binding of both CREB1 and Sp1 transcription factors at the promoter region of the XPC gene for both HTB4 and HTB9 cells. The results of our immunohistochemistry (IHC) staining studies further revealed a strong correlation between the over-expression of HDAC4 and increased bladder cancer occurrence $(p$ $<0.001)$ as well as a marginal significance of increasing incidence of HDAC4 positivity seen with an increase in severity of bladder cancer $(p=0.08)$. In addition, the results of our caspase 3 activation studies demonstrated that prior treatment with VPA increased the anticancer drug cisplatin-induced activation of caspase 3 in both HTB4 and HTB9 cells. All of these results suggest that the HDACs negatively regulate transcription of the XPC gene in bladder cancer cells and contribute to the severity of bladder tumors.
\end{abstract}

\section{Introduction}

Bladder cancer is one of the most common malignancies. Worldwide, more than 350,000 new cases of bladder cancer are diagnosed each year with over 145,000 deaths resulting from the disease [1]. Bladder cancer is strongly associated with exposure to environmental factors. Cigarette smoking is the single most important environmental factor in causing bladder cancer [2]. Exposure to other environmental factors, especially polycyclic aromatic amines, such as aniline, benzidine, and turoline, is also closely correlated with bladder cancer risk [2]. The mechanism by which the exposure to environmental factors causes development of bladder cancer is unknown. It is believed that the exposure to the environment makes the bladder tissue more

\footnotetext{
* Correspondence: g.wang@wayne.edu

'Institute of Environmental Health Sciences, Wayne State University, 259 Mack Avenue, Detroit, Ml 48201, USA

Full list of author information is available at the end of the article
}

susceptible to environmental carcinogens and the DNA damage generated by these carcinogens and/or their metabolites causes initiation and progression of bladder cancer.

Nucleotide excision repair (NER) is the major DNA repair pathway in repairing bulky DNA damage generated by most environmental carcinogens, including DNA damage generated by cigarette smoking [3-5]. The NER pathway can be further distinguished into the transcription-coupled NER (TCR) and global genome NER (GGR) sub-pathways. The TCR pathway quickly repairs DNA damage in highly transcribed DNA sequences, whereas the GGR pathway repairs DNA damage throughout the entire genome, but at a dramatically decreased rate [6,7]. In TCR, DNA damage is recognized by a stalled transcription event $[8,9]$, whereas in GGR, DNA damage is recognized by XPC, a DNA damage recognition protein $[10,11]$. The DNA damage recognition signal further recruits several important NER

\section{Biomed Central}


components, including XPA, RPA, TFIIH, XPG, and XPF-ERCC1, to the damage site [4]. The dual incisions made by XPG [12] and XPF-ERCC1 $[13,14]$ generates a 22-24nt single-stranded gap. The DNA polymerases (pol $\delta$ and $\varepsilon$ ) fill the gap using the complementary DNA strand as a template and DNA ligase seals the flanking gaps to complete the DNA repair process [15].

Beyond its role in DNA repair, the DNA damage recognition signal of XPC protein is also required for many DNA damage-induced cellular responses, including cell cycle checkpoint regulation and apoptosis [16]. Activation of p53, a key DNA damage signaling-mediator [4], is involved in the XPC protein DNA damage recognition-induced signaling process [16]. The proteinprotein interactions of the XPC protein with other NER components, most notably TFIIH [17-19], seem to play a critical role in the DNA damage-mediated signal transduction process. The active p53 protein further induces transcription of important DNA damageresponsive genes to result in relevant cellular responses. Therefore, the presence of a functional XPC protein is essential not only for DNA repair, but also for DNA damage-mediated signal transduction, which results in restoration of the disrupted cellular functions or elimination of the severely damaged cells.

Deficiency or attenuation of the XPC protein has been strongly associated with high incidence of cancer. The patients of xeroderma pigmentosum (XP), including XPC patients, display an over 1000 -fold increase in skin cancer incidence $[5,20,21]$. The XPC patients also display high incidences of lung, liver, and colon cancer [5]. Transgenic animal studies reveal that XPC gene knockout mice $\left(\mathrm{XPC}^{-1-}\right)$ develop significantly higher levels of skin, liver, and lung tumors than their wild type $\left(\mathrm{XPC}^{+/+}\right)$or XPC heterozygous $\left(\mathrm{XPC}^{+/-}\right)$littermates when exposed to chemical carcinogens [22-27]. The results obtained from others and our recent studies reveal reduced levels of XPC protein in the tumors for a majority of bladder and lung cancer patients [27-29]. All of these results suggest that the presence of a functional XPC protein is essential in protecting cells against environmental carcinogencaused cancer development, and XPC protein attenuation and its deficiency contributes to cancer development, especially for cancers strongly associated with environmental factors such as lung and bladder cancer. In addition, reduced levels of XPC protein may also be a contributing factor in tumor cell resistance to many commonly used DNA-damaging anticancer drugs because of the role of the XPC protein in initiating important cellular responses such as apoptosis following the treatment with these drugs.

The mechanism that leads to reduced levels of XPC protein in the tumors of bladder cancer patients is unknown. The knowledge obtained from recent epigenetic studies suggests that epigenetic regulation may play an important role in this aspect [30-35]. The epigenetic regulation involves several different mechanisms, including DNA methylation, histone acetylation/ deacetylation, and microRNA (miRNA). In regards to histone acetylation/deacetylation, it is widely known that the acetylation status of histones significantly affects transcription of target genes [36]. The binding of acetylated histones at the promoter region of target genes leads to a more opened chromatin structure, which enhances transcription of the target gene. In contrast, the binding of deacetylated histones at the promoter region causes a more closed DNA structure, which causes silencing of the target gene. Deacetylation of the histones occurs through histone deacetylases (HDACs), a super family of proteins [37]. Abnormal levels of deacetylases have been reported in many types of cancer, which suggests a possible role of HDACs in the disease process $[37,38]$.

In this study, we focused on determining the role of histone deacetylases (HDACs) in XPC gene silencing and bladder cancer development. Using HTB4 (T24) and HTB9 bladder carcinoma cells, the results of our HDAC inhibitor studies demonstrated that treatment with a HDAC inhibitor, valproic acid (VPA), caused increased transcription of the XPC gene in these cells. The results obtained from our chromatin immunoprecipitation (ChIP) studies revealed that the treatment of VPA enhanced the binding of transcription factors CREB-1 and Sp1 at the promoter region of the XPC gene in both HTB4 and HTB9 cells. The results obtained from our immunohistochemistry (IHC) staining studies further revealed a strong correlation between the over-expression of HDAC4 and the occurrence of bladder transitional cell carcinomas $(p<0.001)$ as well as a marginal significance between the over-expression of HDAC4 and the severity of the bladder tumors $(p=$ 0.08). In addition, the results of our caspase 3 activation studies demonstrated that the prior treatment with VPA enhanced the anticancer drug cisplatin-induced activation of caspase 3 in both HTB4 and HTB9 cells. All of these results suggest that over-expression of the HDAC4 contributes to the XPC gene silencing and the development of bladder carcinomas, and inhibiting the HDAC activities with the HDAC inhibitor VPA sensitizes the bladder carcinoma cells to anticancer drug cisplatin. These results provide an important mechanism for the XPC gene silencing in bladder cancer cells and suggest an important mechanism in bladder cancer development. In addition, the results obtained from this study also suggest that inhibiting HDAC activity with HDAC inhibitor may greatly benefit the bladder cancer treatment through its sensitization of bladder cancer cells to 
many DNA-damaging anticancer drugs, such as cisplatin.

\section{Materials and methods Cell lines and Oligonucleotides}

The HTB4 (T24), HTB9, HTB2, HTB3, HTB5, HT1197, and HT1376 bladder cancer cells were purchased from American Type Culture Collection (ATCC) (Rockville, MD). The GM00637 human fibroblast cells were purchased from the Coriell Institute for Medical Research (Camden, NJ). The HTB2 and HTB4 cells were cultured in a McCoy's $5 \mathrm{~A}$ medium supplemented with $10 \%$ FBS at $37^{\circ} \mathrm{C}$ with $5 \% \mathrm{CO}_{2}$. The HTB9 cells were cultured in RPMI1640 medium supplemented with $1 \times$ non-essential amino acids (NEAA) and $10 \% \mathrm{FBS}$ at $37^{\circ} \mathrm{C}$ with $5 \%$ $\mathrm{CO}_{2}$. The HTB3, HTB5, HT1197, and HT1376 bladder cancer cells were cultured in minimal essential medium (MEM) supplemented with $10 \%$ FBS and $1 \times$ NEAA at $37^{\circ} \mathrm{C}$ with $5 \% \mathrm{CO}_{2}$. The GM00637 cells were cultured in MEM supplemented with $10 \%$ FBS, $2 \times$ essential amino acids (EAA), 2x NEAA, and $2 \mathrm{x}$ vitamins (Vt) at $37^{\circ} \mathrm{C}$ with $5 \% \mathrm{CO}_{2}$.

The oligonucleotides used in this study are listed in Table 1 and were synthesized by Retrogen, Inc. (San Diego, CA). The primers used for determining the level of XPC mRNA by real time PCR were designed to bind to the XPC mRNA sequence at exon 5 and exon 6 thus amplifying a $120 \mathrm{bp}$ DNA fragment. The primers used for determining the level of XPA mRNA by real time PCR were designed to bind to the XPA mRNA at exon 3 and exon 4 in order to amplify a 110 bp DNA fragment. The primers used for detection of the immunoprecipitation XPC gene promoter sequence were designed to bind to the XPC gene 5' regulatory region sequence at the -95 to -75 region and the +80 to +50 region to amplify a 175 bp DNA fragment.

\section{VPA treatment}

The VPA was purchased from Sigma Corp. (St. Louis, MO). The HTB4 and HTB9 cells were seeded onto 100 $\mathrm{mm}$ cell culture dishes at a density of $1 \times 10^{6}$ cells/dish

Table 1 Oligonucleotides used in the study.

\begin{tabular}{|c|c|}
\hline Name of oligonucleotide & Sequences of the oligonucleotide \\
\hline \multicolumn{2}{|c|}{ 1. Primers used for the real time PCR study } \\
\hline XPC primer 1 & 5'-GTGACCTCAAGAAGGCACAC-3' \\
\hline XPC primer 2 & 5'-CTCACGTCACCCAGCACAGG-3' \\
\hline XPA primer 1 & 5'-CTGCGGCTACTGGAGGCATGG-3' \\
\hline XPA primer 2 & 5'-CCATAACAGGTCCTGGTTGATG-3' \\
\hline \multicolumn{2}{|c|}{$\begin{array}{l}\text { 2. Primers used for amplifying the XPC gene } 5 \text { ' regulatory region in th } \\
\text { IP study }\end{array}$} \\
\hline XPC IP primer 1 & 5'-CGTGGCCAAGCGCACCGCCTC-3' \\
\hline XPC IP primer 2 & 5'-GGCCTTGCTCTTGGCCTTG-3' \\
\hline
\end{tabular}

and incubated at $37^{\circ} \mathrm{C}$ overnight. The VPA was added to the cell culture medium to a final concentration of 5 $\mathrm{mM}$. The cells were cultured in the VPA-containing medium for 48 hours and then used for further studies.

\section{Real time quantitative PCR assay}

Total RNA was isolated from both untreated and VPAtreated HTB4 and HTB9 bladder cancer cells using an RNeasy mini isolation kit (Qiagen). A reverse transcription-based quantitative PCR (real time PCR) was then performed to determine the mRNA levels of both $x p c$ and $x p a$ genes from each RNA sample using a Sybr green-based DNA quantification method (Applied Biosystems, Foster City, CA). The mRNA level of the $\beta$-actin gene was also determined for each RNA sample by using the real time PCR. The reverse transcription assay was carried out using $2 \mu \mathrm{g}$ of total RNA utilizing the protocol suggested by the manufacturer (Applied Biosystems). The PCR procedure was performed using Taq-Man Universal PCR master mix with $100 \mathrm{ng}$ cDNA in a total volume of $20 \mu \mathrm{l}$. The PCR assays were completed using the ABI prism 7500 Fast PCR system with the following conditions: $2 \mathrm{~min}$ at $94^{\circ} \mathrm{C}$, followed by 40 cycles of 15 seconds at $95^{\circ} \mathrm{C}$, 30 seconds at $56^{\circ} \mathrm{C}$, and 60 seconds at $72^{\circ} \mathrm{C}$. The real time PCR data was analyzed using a comparative cycle threshold $\left(C_{t}\right)$ method. Relative quantification was performed to determine gene expression between untreated and VPA-treated cells. The actin gene was used as an internal control for normalization. Relative transcriptions of the XPC and XPA mRNAs were calculated as $2^{-\Delta \Delta C t}$ where $\Delta C_{t}$ was calculated by subtracting the average actin gene $C_{t}$ from the average $\mathrm{XPC}$ or XPA gene $\mathrm{C}_{t}$ value in the same cell line. The $\Delta \Delta C_{t}$ was obtained by the $\Delta C_{t}$ of the VPA-treated cells subtracted from the $\Delta C_{t}$ of the untreated cells.

\section{Western blot hybridization and quantification of the protein}

Cells were harvested and lysed in RIPA cell lysis buffer (1xPBS, 1\% NP40, 0.5\% deoxycholic acid, 0.1\% SDS). The cell lysates $(30 \mu \mathrm{g}$ total protein) were analyzed by SDS-PAGE using a $10 \%$ gel. The proteins were transferred to a PVDF membrane and hybridized with the indicated antibodies for detection of the desired target proteins. The same membrane was then soaked in a stripping solution (62.5 mM Tris, $\mathrm{pH}$ 6.8, 2\% SDS, 0.7\% 2-mercaptoethanol) at $50^{\circ} \mathrm{C}$ for $30 \mathrm{~min}$ and then hybridized with a $\beta$-actin antibody (Oncogene, Cambridge, MA) to determine the level of $\beta$-actin in each sample. Quantification of the western results was performed using a Kodak Image Station 440CF system and the level of the target protein in each cell lysate was expressed as a relative level to that of $\beta$-actin in the 
same cell lysate. The level of XPC protein in the VPAtreated cells was calculated as a percentage compared to that of the XPC protein in the untreated cells. The statistical analysis of the western data was done using GraphPad PRISM 4.0 software.

\section{Chromatin immunoprecipitation (ChIP)}

The cells were harvested and washed in 1xPBS buffer once. The cells were then resuspended into 1xPBS buffer containing $1 \%$ formaldehyde and incubated at $37^{\circ} \mathrm{C}$ for 15 minutes. The cells were collected and washed three times with $1 x$ PBS buffer. The cells were then resuspended into SDS lysis buffer $\left(1 \times 10^{6}\right.$ cells $\left./ 200 \mu \mathrm{l}\right)$ and incubated on ice for 10 minutes. The cells were sonicated in order to shear the genomic DNA to lengths of 200-1000 bp. The cell lysates were centrifuged at $4^{\circ} \mathrm{C}$ for 10 minutes and the supernatants were collected. For the ChIP assay, cell lysate $(200 \mu \mathrm{l})$ was diluted at a ratio of $1: 10$ in the ChIP dilution buffer $(0.01 \%$ SDS, $1.1 \%$ Triton X-100, $1.2 \mathrm{mM}$ EDTA, $16.7 \mathrm{mM}$ Tris- $\mathrm{HCl}$, pH8.1, $167 \mathrm{mM} \mathrm{NaCl}$ ) and incubated with either Protein A-conjugated agarose beads (for Sp1) or Protein G-conjugated agarose beads (for CREB1) at $4^{\circ} \mathrm{C}$ for $60 \mathrm{~min}$ utes. The cell lysates were centrifuged at $4^{\circ} \mathrm{C}$ for 5 minutes to remove the agarose beads. The cell lysates were then incubated with $2 \mu \mathrm{g}$ of CREB1 antibody (X12 from Santa Cruz) or Sp1 antibody (H-225 from Santa Cruz) at $4^{\circ} \mathrm{C}$ overnight using a rotating mixer. The Protein A-conjugated agarose beads (for Sp1) or Protein G-conjugated agarose beads (for CREB1) were then added and the reactants were incubated at $4{ }^{\circ} \mathrm{C}$ for 2 hours with a rotating mixer. The beads were collected and washed three time in $1 \times$ PBS buffer and three times in ChIP washing buffer $(0.1 \%$ SDS, $1 \%$ Triton X-100, 2 mM EDTA, $20 \mathrm{mM}$ Tris- $\mathrm{HCl}, \mathrm{pH} 8.1,150 \mathrm{mM} \mathrm{NaCl}$ ). Half of the beads were analyzed by western blot to determine the amount of the CREB1 or Sp1 proteins precipitated by the ChIP protocol. The remainder of the beads were resuspended into $200 \mu \mathrm{l}$ of DNA elution buffer $\left(0.1 \mathrm{M} \mathrm{Na}_{2} \mathrm{CO}_{3}, 1 \%\right.$ SDS, $\left.200 \mathrm{mM} \mathrm{NaCl}\right)$ and incubated at $65^{\circ} \mathrm{C}$ for 6 hours to reverse the proteinDNA cross-links. The DNA was recovered by phenol/ chloroform extraction and ethanol precipitation. The relative level of XPC gene promoter region DNA coprecipitated with the beads was determined by a quantitative PCR (qPCR) protocol using the Applied Biosystems' Fast 7500 Real Time PCR system (Applied Biosystems, Foster City, CA). The level of the XPC gene promoter region DNA co-precipitated with the CREB1 or $\mathrm{Sp} 1$ in the untreated cells was accounted as $100 \%$ and the level of the XPC gene promoter region DNA co-precipitated with the beads in the VPA-treated cells was calculated as a fold change relative to that of the untreated cells.

\section{Immunohistochemistry (IHC) staining}

The bladder tumor tissue arrays BL208, BL2081 and BL2082 were purchased from US BioMax Inc. (Rockville, MD) and were used in the IHC staining study. The formalin-fixed paraffin-embedded (FFPE) bladder tumor tissue array slides were first deparaffinized in 100\% xylenes; the slides were then hydrated through a series of graded alcohols $(100 \%, 95 \%, 80 \%, 70 \%$, and $30 \%)$ for 5 minutes each. The slides were washed once in $\mathrm{H}_{2} \mathrm{O}$ for 5 minutes. The slides were then incubated in 10 $\mathrm{mM}$ sodium citrate buffer (pH6.0) for 15 minutes at $95^{\circ}$ $\mathrm{C}$ to unmask the antigen. The bladder tumor tissue array slides were then incubated in $1 \%$ hydrogen peroxide at room temperature for 10 minutes to quench endogenous peroxidase activity. The slides were incubated in $1.5 \%$ normal blocking serum in $1 \mathrm{xPBS}$ for 1 hour and then incubated with the primary antibody at 1:100 dilution in 1xPBS for 30 minutes. The slides were washed in $1 \times$ PBS three times and then incubated with a biotin-conjugated secondary antibody (Santa Cruz) at room temperature for 30 minutes. The slides were then washed three times in 1xPBS and incubated with an avidin-biotin enzyme reagent (Santa Cruz) for 30 minutes. The slides were incubated in peroxidase substrate (Santa Cruz) for 1 to 10 minutes until the desired stain intensity developed. The slides were counterstained in Gill's formulation \#2 hematoxylin (Santa Cruz) for 10 seconds and then washed in deionized $\mathrm{H}_{2} \mathrm{O}$ with several $\mathrm{H}_{2} \mathrm{O}$ changes. The slides were dehydrated through graded alcohols (30-100\%) and xylenes and mounted with glass coverslips using a Clarion permanent mounting medium (Santa Cruz, CA). The HDAC-positive cells were determined using light microscopy. Two hundred cells were counted from each tissue specimen. A HDAC-negative tissue specimen was established if $>20 \%$ of the counted cells were HDAC-positive cells and a HDAC-positive tissue specimen was established if $<20 \%$ of the counted cells were HDAC-positive cells.

\section{Caspase-3 assay}

The caspase- 3 activity was measured using a protocol described previously $[39,40]$. Essentially, the cells were harvested 40 hours after the cisplatin treatment and lysed in insect cell lysis buffer (BD Biosciences). The protein concentrations of the cell lysates were determined. The caspase- 3 assay was carried out in a 96-well plate using fluorogenic Ac-DEVD-AMC as a substrate (BD Biosciences). Caspase-3 activity was determined by a spectrafluorometer (Molecular Devices) for detection of free AMC released from the substrate during a 15minute incubation period at $37^{\circ} \mathrm{C}$ with an excitation wavelength of $380 \mathrm{~nm}$ and an emission wavelength of 430-460 nm. Caspase-3 activity was measured as nanomole of $\mathrm{AMC} / \mathrm{min} / \mathrm{mg}$ protein 


\section{Statistical analysis}

Results were expressed as the mean + standard deviation (S.D.). Statistically significant differences were determined using a one-factor analysis of variance with $p<0.01$. The data was obtained from at least three independent experiments.

\section{Results}

Induced transcription of XPC gene in the VPA-treated HTB4 and HTB9 bladder cancer cells

In order to determine the role that the HDACs may play in XPC gene silencing and bladder cancer development, we first determined the effect of HDAC inhibitor treatment on activation of XPC gene transcription in HTB4 and HTB9 bladder cancer cells. Both HTB4 and HTB9 cancer cells were treated with the HDAC inhibitor of VPA ( $5 \mathrm{mM}$ ) for 48 hours and the total RNA was isolated. Total RNA was also isolated from the untreated HTB4 and HTB9 cells. A reverse transcription-based quantitative PCR (real time PCR) was performed to determine the level of the XPC mRNA in each RNA sample (Table 2). The level of XPA mRNA was also determined for each RNA sample in the study. The XPA protein is an important NER component but the level of XPA mRNA was not affected by the DNA damaging treatment [16]. The level of $\beta$-actin mRNA was determined for each RNA sample as an internal control. The level of the XPC mRNA increased $2.8 \pm 0.4$ and $2.4 \pm 0.3$ fold in the HTB4 and HTB9 cells respectively with the VPA treatment (Table 2). In contrast, the level of the XPA mRNA was not significantly altered in these cells following the VPA treatment (Table 2). These results suggest that the HDACs indeed play an important role in XPC gene silencing for both HTB4 and HTB9 bladder cancer cells, and treatment with the VPA HDAC inhibitor causes activation of the XPC transcription in both bladder cancer cell lines.

The VPA treatment caused enhanced binding of the CREB 1 and Sp1 transcription factors at the promoter region of the endogenous XPC gene in both HTB4 and HTB9 bladder cancer cells

To determine the mechanism through which the HDACs inhibit transcription of the XPC gene, we

Table 2 The effect of valproic acid (VPA) treatment on transcription of XPC and XPA genes in both HTB4 and HTB9 bladder cancer cells.

\begin{tabular}{ccccc}
\hline Genes & \multicolumn{2}{c}{ HTB4 } & \multicolumn{2}{c}{ HTB5 } \\
\cline { 2 - 5 } & $\begin{array}{c}\text { No } \\
\text { treatment }\end{array}$ & $\begin{array}{c}\text { VPA } \\
\text { treatment }\end{array}$ & $\begin{array}{c}\text { No } \\
\text { treatment }\end{array}$ & $\begin{array}{c}\text { VPA } \\
\text { treatment }\end{array}$ \\
\hline $\begin{array}{c}\text { XPC } \\
\text { mRNA }\end{array}$ & 1 & $2.8 \pm 0.4$ & 1 & $2.4 \pm 0.3$ \\
\hline $\begin{array}{c}\text { XPA } \\
\text { mRNA }\end{array}$ & 1 & $1.1 \pm 0.1$ & 1 & $0.9 \pm 0.1$ \\
\hline
\end{tabular}

further performed a chromatin immunoprecipitation (ChIP)-based transcription factor binding study. We chose both CREB1 and Sp1 transcription factors for our ChIP study because the consensus sequences for both transcription factors are present at the $5^{\prime}$ promoter region of the XPC gene (Figure 1) and are likely to be involved in the transcription regulation of the XPC gene. Some studies also revealed the overlapping in binding to DNA targets between the HDAC4 and the Sp1 [41-46]. The HTB4 and HTB9 cells were treated with the VPA $(5 \mathrm{mM})$ for 48 hours and fixed in $1 \%$ formaldehyde. As a control, the untreated HTB4 and HTB9 cells were also harvested and fixed in 1\% formaldehyde. The cells were sonicated to shear the chromosomal DNA into small fragments. A ChIP protocol was performed to pull down the CREB1 or the Sp1 transcription factor using antibodies against the individual transcription factors. Half of the beads obtained from the ChIP protocol were analyzed by western blots to determine the amount of the transcription factor pulled down by the ChIP protocol (Figure 2). The remainder of the beads was resuspended into an elution buffer $(0.1 \mathrm{M}$ $\mathrm{Na}_{2} \mathrm{CO}_{3}, 1 \% \mathrm{SDS}, 200 \mathrm{mM} \mathrm{NaCl}$ ) and the DNA co-precipitated with the transcription factors was recovered. The DNA was analyzed by a quantitative PCR (qPCR) protocol to determine the amount of XPC gene promoter region DNA co-precipitated with the transcription factors (Table 3). The results of our western blots revealed that similar amounts of the CREB1 and Sp1 were pulled down from both untreated and VPA-treated cells for both HTB4 and HTB9 cells, suggesting a very successful ChIP protocol (Figure 2). The results of our qPCR studies, however, indicated a very different pattern of XPC gene promoter region DNA co-precipitation following the VPA treatment. When the CREB1 antibody was used in the ChIP study, the VPA treatment resulted in a $4.6 \pm 0.4$ and $2.2 \pm 0.4$ fold increase of the co-precipitated XPC gene promoter region DNA in the HTB4 and HTB9 cells respectively (Table 3 ); when the Sp1

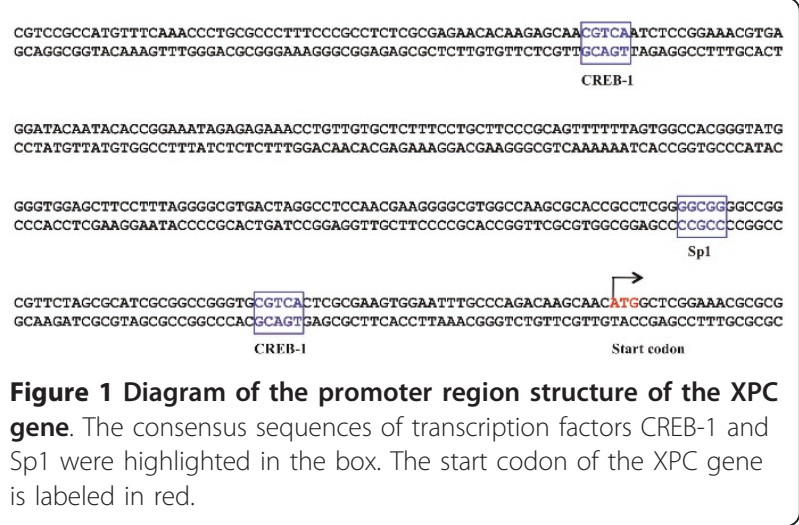


(a) Chromatin Immunoprecipitation (ChIP) with CREB1 antibody

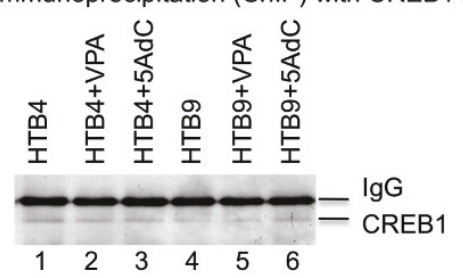

(b) Chromatin Immunoprecipitation (ChIP) with Sp1 antibody

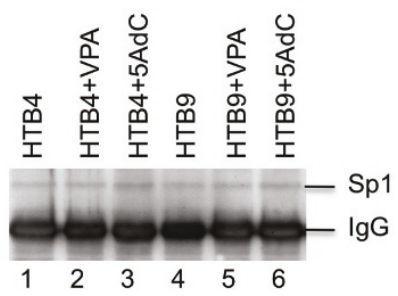

Figure 2 Detection of CREB-1 and Sp1 protein obtained from the chromatin immunoprecipitation (ChIP). A ChIP protocol was performed to pull down the CREB-1 and Sp1 proteins from the individual cell lysates using antibodies against CREB-1 and Sp1 respectively. Half of the agarose beads obtained from the ChIP study were analyzed by western blots to determine the amount of the transcription factors precipitated from individual cell lysates. The remainder of the beads was analyzed by real time PCR to determine the amount of the XPC gene promoter DNA coprecipitated with the individual transcription factors.

antibody was used in the ChIP study, the VPA treatment caused a $2.2 \pm 0.3$ and $2.0 \pm 0.3$ fold increase of the co-precipitated XPC gene promoter region DNA in the HTB4 and HTB9 cells respectively. These results indicate that the VPA treatment enhances the binding of the CREB1 and Sp1 transcription factors at the promoter region of the endogenous XPC gene in both HTB4 and HTB9 cells, suggesting that inhibiting the binding of CREB1 and Sp1 transcription factors to their

\begin{tabular}{|c|c|c|c|c|}
\hline \multirow{2}{*}{$\begin{array}{c}\text { IP } \\
\text { antigen }\end{array}$} & \multicolumn{2}{|c|}{ HTB4 } & \multicolumn{2}{|c|}{ НTB9 } \\
\hline & $\begin{array}{c}\text { No } \\
\text { treatment }\end{array}$ & $\begin{array}{c}\text { VPA } \\
\text { treatment }\end{array}$ & $\begin{array}{c}\text { No } \\
\text { treatment }\end{array}$ & $\begin{array}{c}\text { VPA } \\
\text { treatment }\end{array}$ \\
\hline CREB1 & 1 & $4.6 \pm 0.4$ & 1 & $2.2 \pm 0.2$ \\
\hline Sp1 & 1 & $2.2 \pm 0.3$ & 1 & $2.0 \pm 0.3$ \\
\hline
\end{tabular}

${ }^{\text {a }}$ The level of XPC gene $5^{\prime}$ regulatory region DNA co-precipitated in the untreated cells was counted as 1 and the level of XPC gene $5^{\prime}$ regulatory region DNA co-precipitated in the VPA-treated cells was calculated as fold change to that of the untreated cells for each cell line. The fold change was expressed as Mean \pm S.D. The results were from three independent IP experiments. consensus sequences plays an important role in the HDACs-mediated XPC gene silencing.

The correlation between the over-expression of HDAC4 and the development of bladder cancer

To further determine the role of HDACs in XPC gene silencing and bladder cancer development, we determined the correlation between the presence of HDACs and the occurrence of bladder cancer using bladder tumor tissue arrays with an immunohistochemistry (IHC) staining procedure (Figure 3 and Table 4). The bladder tumor tissue arrays were purchased from US BioMax, Inc. (Rockville, MD) and used in this study. Both HDAC2 and HDAC4 were chosen for this study because the work of others has revealed abnormal levels of these proteins in many types of cancer [47-55]. The results of our IHC study indicated that the frequency of the HDAC4-positive tissue specimens was much higher in the bladder tumors than in the normal bladder tissues (Figure 3 panel and Table 4). The statistical analysis of the data further revealed a significant difference in the frequency of HDAC4-positive tissue specimens between normal and cancerous bladder tissues $(p<0.001)$ as well as a marginal significance between the increasing incidence of HDAC4 positivity and the increasing severity of the bladder tumors $(p=0.08)$ (Table 4$)$. The frequency of the HDAC2-positive specimens, however, was similar between normal and cancerous bladder tissues (data not shown). These results suggest that overexpression of the HDAC4 is strongly correlated with the development of bladder cancer.

\section{The HDAC4 was over-expressed in most of the bladder cancer cells}

The results of our IHC studies revealed strong correlation between over-expression of the HDAC4 and the occurrence of bladder tumors. To validate the IHC result, we further determined expression of several HDACs, including HDAC4, HDAC1, and HDAC2, in the HTB4, HTB9, HTB2, HTB3, HTB5, HT1197 and HT1376 bladder cancer cells (Figure 4). The expression of these HDACs in the GM00637 normal human fibroblast cells was also determined in the western blotting study and used as a control. The results obtained from our western blots study indicated that the protein levels of the HDAC1 and HDAC2 were similar in all the tested cells (Figure 4 middle panels). In contrast, the expression levels of HDAC4 were greatly increased in most of the tested bladder cancer cells except the HTB4 bladder cancer cells in comparison to that of the GM00637 normal human fibroblast cells (Figure 4 top panel). This result confirmed our IHC results and suggested the important role of HDAC4 over-expression in the bladder cancer development. 


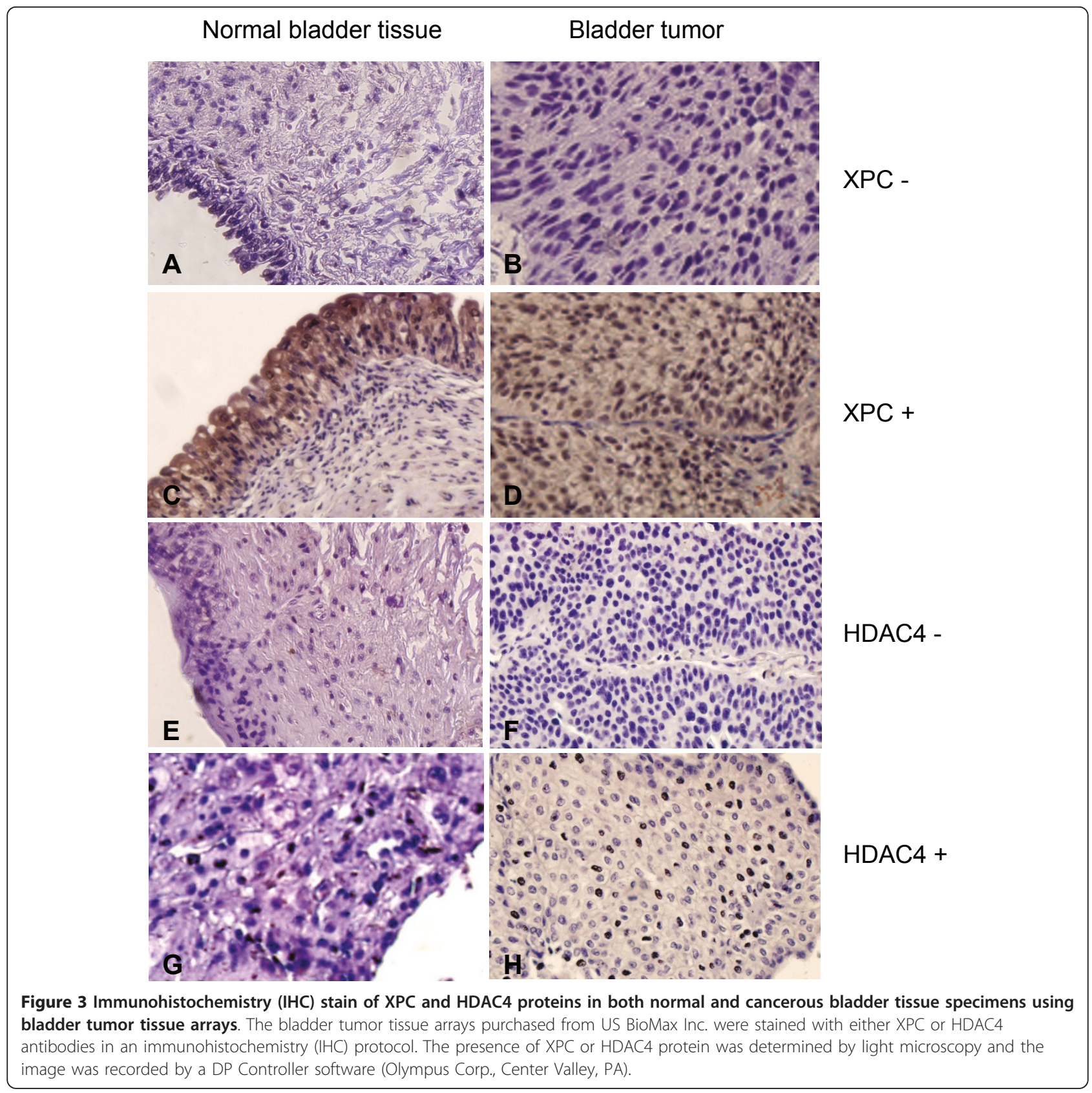

Table 4 Determination of the presence of the HDAC4 in both normal and cancerous bladder tissues from bladder tumor tissue arrays.

\begin{tabular}{llll}
\hline Type of bladder tissues & \# of HDAC4(+) & \# of Total tissues & \% of HDAC4(+) \\
\hline Normal bladder tissues & 1 & 23 & 4.3 \\
\hline Transitional cell carcinomas (Grade 1) & 26 & 58 & 44.8 \\
\hline Transitional cell carcinomas (Grade 2) & 28 & 59 & 47.5 \\
\hline Transitional cell carcinomas (Grade 3) & 8 & 25 & 32.0 \\
\hline$P$ value & $p^{\Delta}<0.001$ & & \\
& $p^{\sigma}=0.08$ & & \\
\hline
\end{tabular}

Note: $p^{\Delta}$ value is the comparison between the group of normal bladder tissues and the group of cancerous bladder tissues. $p^{\sigma}$ is the comparison among the groups of normal bladder tissues, Grade 1, Grade 2, and Grade 3 bladder carcinomas. 


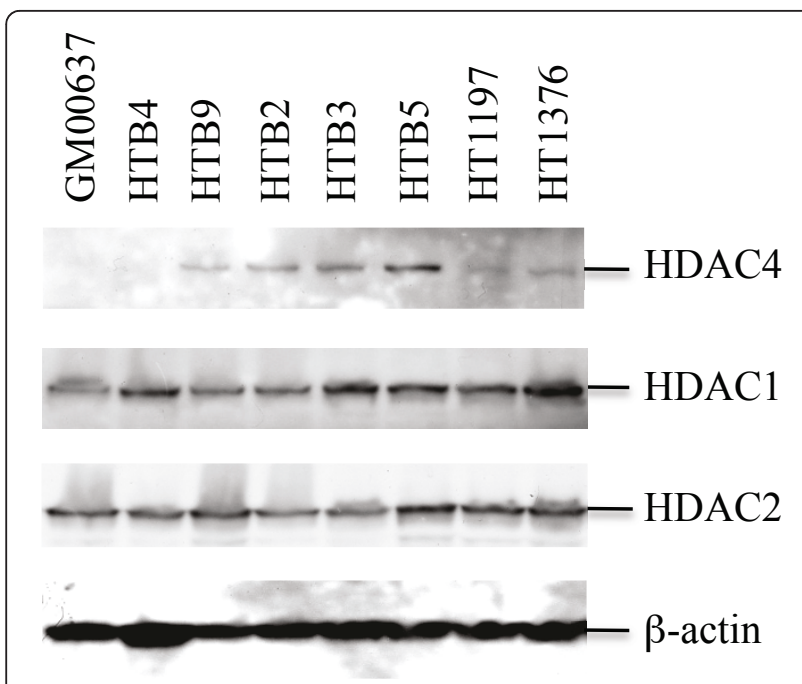

Figure 4 Detection of expression of HDAC4, HDAC1, and HDAC2 in various bladder cancer cells. The cell lysates prepared from the HTB2, HTB3, HTB4, HTB5, HTB9, HT1197, HT1376 bladder cancer cells and GM00637 normal human fibroblast cells (30 $\mu \mathrm{g}$ total protein) were analyzed by western blots to determine the protein levels of HDAC4, HDAC1, HDAC2, and $\beta$-actin in each cell lysate. The antibodies against HDAC4 (A-4), HDAC1 (C-19), HDAC2 $(\mathrm{H}-54)$ and $\beta$-actin $(\mathrm{C}-2)$ were purchased from Santa Cruz Biotechnology, Inc. (Santa Cruz, CA) and used in the western blots study.

Prior treatment with the HDAC inhibitor VPA enhanced cisplatin-induced apoptosis of bladder cancer cells

Extensive studies have demonstrated the cisplatininduced apoptosis as major mechanism in cell killing [16,39,56-58]. Because of the important function of XPC protein in the cisplatin-caused apoptosis [16] and the role HDACs in XPC gene silencing, we further investigated the effect of the HDAC inhibitor VPA in cisplatin-induced apoptosis of bladder cancer cells. The HTB4 and HTB9 bladder cancer cells were treated with VPA ( $5 \mathrm{mM}$ ) for 48 hours before they were treated with cisplatin. The cells were harvested 40 hours after the cisplatin treatment and the caspase-3 activity was determined (Figure 5). The caspase- 3 activity was also determined from the HBT4 and HTB9 cells that were treated with cisplatin but without the prior VPA treatment (Figure 5). The cisplatin treatment itself caused an increase in caspase-3 activity in both HTB4 and HTB9 bladder cancer cells at high concentrations $(20 \mu \mathrm{M}$ and $40 \mu \mathrm{M})$ but not at lower concentrations $(5 \mu \mathrm{M}$ and 10 $\mu \mathrm{M}$ ) (Figure 5). When these cells were treated with VPA prior to the cisplatin treatment, however, the caspase-3 activity was significantly increased at lower concentrations as well (Figure 5). For example, when treated only with cisplatin at $10 \mu \mathrm{M}$, the caspase 3 activity was increased by a 1.5 and 2 fold in the HTB4 and HTB9 cells respectively; when the cells were treated with 5

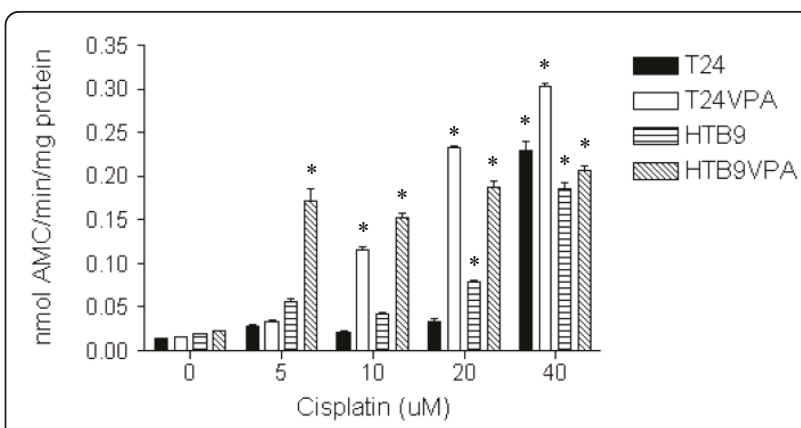

Figure 5 The cisplatin-induced caspase 3 activity in both untreated and VPA-treated HTB4 and HTB9 bladder cancer cells. The VPA treatment ( $5 \mathrm{mM}$ ) was done 24 hours prior to the cisplatin treatment. The cells were treated with cisplatin at the indicated concentrations for 3 hours and then cultured in the cell culture incubator for 40 hours before the cells were harvested and the caspase 3 activity was measured. The caspase 3 activity was measured as nanomole of $\mathrm{AMC} /$ minute/mg of protein. (* statistical difference to that of the untreated cells with $p$ value $<0.01$ ).

$\mathrm{mM}$ VPA prior to the cisplatin treatment, however, the $10 \mu \mathrm{M}$ cisplatin treatment resulted in a 7.3 and 6.6 fold increase of the caspase- 3 activity in the HTB4 and HTB9 cells respectively (Figure 5). These results suggest that the prior treatment of HTB4 and HTB9 bladder cancer cells with the HDAC inhibitor VPA sensitizes these bladder cancer cells to the anticancer drug cisplatin.

\section{Discussion}

In this work we have determined the role of HDACs in XPC gene silencing and bladder cancer development. The results obtained from our HDAC inhibitor treatment studies revealed that the VPA treatment led to an increase in transcription of the XPC mRNA in both HTB4 and HTB9 bladder cancer cells. The results obtained from our ChIP study demonstrated that the VPA treatment resulted in an increase in binding of the CREB1 and Sp1 transcription factors at the 5' regulatory region of the XPC gene in both HTB4 and HTB9 cells. The results of our IHC studies further indicated a strong correlation between the over-expression of the HDAC4 and the occurrence of urinary bladder transitional cell carcinomas. In addition, the results obtained from our caspase- 3 activation studies also demonstrated that the pre-treatment of HTB4 and HTB9 bladder cancer cells with VPA enhanced the anticancer drug cisplatin-induced activation of caspase-3, an important apoptotic caspase indicative of irreversible apoptosis. Given the important role of the XPC protein in protecting cells against many environmental carcinogeninduced deleterious effects and the significance of the HDACs in epigenetic gene transcription regulation [31-33], these results suggest that the HDACs play an 
important role in XPC gene silencing and bladder cancer development. Therefore, these results provide an important mechanism of XPC gene silencing and bladder cancer development. Because of the essential role of the XPC protein in initiating DNA damage-induced cellular responses [16], these results further suggest that silencing of the XPC gene may provide a critical early event for initiation of bladder tumors. In addition, the results obtained from these studies further suggests that reactivation of the XPC gene by HDAC inhibitors may have great benefits for bladder cancer treatment, especially for DNA-damaging anticancer drugs such as cisplatin.

The results of our ChIP studies revealed that the VPA treatment led to an increase in binding of the CREB1 and $\mathrm{Sp} 1$ transcription factors to the 5 regulatory region of the XPC gene. These results suggest that inhibiting the binding of these transcription factors to their consensus sequences plays an important role in the HDACs-caused XPC gene silencing of bladder cancer cells. This provides an important basis for understanding the mechanism of XPC gene silencing in bladder cancer cells. However, it is widely known that the consensus sequences of many transcription factors are present at the promoter region of the XPC gene, whether or not the bindings of these transcription factors are also affected by HDACs, and therefore, contribute to the XPC gene silencing is largely unknown. It may be important to determine the effect of HDACs on the bindings of these individual transcription factors at the promoter region of the XPC gene in order to provide a better understanding of the molecular basis by which the HDACs cause silencing of the XPC gene in bladder cancer cells.

The results of our IHC studies reveal that the frequency of the HDAC4-positive tissue specimens was significantly increased in the urinary bladder transitional cell carcinomas in comparison to normal bladder tissues. However, the results obtained from our IHC study using a HDAC2 antibody did not show a significant change in the frequency of HDAC2-positive tissue specimens between normal and cancerous bladder tissues (data not shown). Given the similarity between the HDAC2 and HDAC4 proteins in both their functions, these results suggest that only certain HDACs are involved in the XPC gene silencing in the urinary bladder transitional cell carcinomas. Since the HDACs family proteins also include several other HDACs, it would be important to determine the correlation between the presence of the individual HDACs and the bladder cancer occurrence for each HDAC in order to provide a better understanding of the role of specific HDACs in XPC gene silencing and bladder cancer development.
The work described in this study was mainly focused on determining the role of HDACs in XPC gene silencing and bladder cancer development. However, it is known that other epigenetic gene regulation mechanisms, including DNA methylation and microRNA (miRNA), can also lead to silencing of the target genes [32,33]. In fact, recently reported results suggest that DNA methylation may play an important role in XPC gene silencing of lung cancer cells [29]. Therefore, future studies also need to determine the roles of these epigenetic regulation mechanisms in XPC gene silencing and bladder cancer development in order to provide a better understanding of the mechanism of XPC gene silencing and bladder cancer development.

Attenuated XPC protein has been observed in many types of cancer, including bladder and lung cancer $[27,59]$. Given the strong correlation between environmental carcinogen exposure and cancer occurrence for both bladder and lung cancer as well as the similarity of the lung and bladder organs in exposure to environmental carcinogens, it is possible that silencing of the XPC gene may play an important role in cancer development for many different types of cancer. Therefore, the knowledge obtained from this study will be important not only for understanding the mechanism of bladder cancer development but also for grasping the mechanism of development of these cancers as well. In addition, the knowledge obtained from this study is also important for detection, treatment, and risk assessment of cancer as well as new anticancer drug design and development.

\section{Acknowledgements \\ We thank Mr. Kim Zukowski for his technical help in the immunohistochemistry staining. Performance of this work was facilitated by the Cell Culture Core, the Imaging and Flow Cytometry Core, and the Microarray and Bioinformatic Core of the Environmental Health Sciences Center in Molecular and Cellular Toxicology with Human Applications at Wayne State University (P30ES06639). This work was supported in part by grant R01ES09699 from NIH (G. W.).}

\section{Author details}

${ }^{1}$ Institute of Environmental Health Sciences, Wayne State University, 259 Mack Avenue, Detroit, MI 48201, USA. ${ }^{2}$ Karmanos Cancer Institute, Wayne State University, 4100 John R Street, Detroit, MI 48201 USA.

\section{Authors' contributions}

XX carried out the VPA and IHC studies, and participated in the design and coordination of the project. LW carried out the cell culture and the participated in the immunoblotting and immunoprecipitation study. JA carried out the statistical analysis of the IHC data. GW participated in the design and coordination of the studies and drafted the manuscript. All authors read and approved the final manuscript.

\section{Competing interests}

The authors declare that they have no competing interests.

Received: 9 February 2011 Accepted: 20 April 2011 Published: 20 April 2011 


\section{References}

1. Ploeg $M$, Aben $\mathrm{KKH}$, Kiemeney LA: The present and future burden of urinary bladder cancer in the world. World J Urol 2009, 27:289-293.

2. Kufe DW, Bast RBJ, Hait WH, Hong WH, Pollock RE, Weichselbaum RR, Holland JF, Frei El: Cancer Medicine 7. BC Decker Inc 2006.

3. Friedberg EC, Walker GC, Siede W: DNA repair and mutagenesis. ASM published, Washington, D.C. First 1995.

4. Sancar A, Lindsey-Boltz LA, Unsal-Kaccmaz K, Linn S: Molecular mechanisms of mammalian DNA repair and the DNA damage checkpoints. Annu Rev Biochem 2004, 73:39-85.

5. Friedberg EC, Walker GC, Siede W, Wood RD, Schultz RA, Ellenberger T: DNA repair and mutagenesis. ASM Press, Washington D.C.

6. Hanawalt PC: Transcription-coupled repair and human disease. Science 1994, 266:1957-1958.

7. Hanawalt PC: Subpathways of nucleotide excision repair and their regulation. Oncogene 2002, 21:8949-8956.

8. Sarker AH, Tsutakawa SE, Kostek S, Ng C, Shin DS, Peris M, Campeau E, Tainer JA, Nogales E, Cooper PK: Recognition of RNA polymerase II and transcription bubbles by XPG, CSB, and TFIIH: insights for transcriptioncoupled repair and Cockayne Syndrome. Mol Cell 2005, 20:187-198.

9. Laine JP, Egly JM: Initiation of DNA repair mediated by a stalled RNA polymerase IIO. EMBO J 2006, 25:387-397.

10. Wood RD: DNA damage recognition during nucleotide excision repair in mammalian cells. Biochimie 1999, 81:39-44.

11. Sugasawa K, Okamoto T, Shimizu Y, Masutani C, Iwai S, Hanaoka F: A multistep damage recognition mechanism for global genomic nucleotide excision repair. Genes Dev 2001, 15:507-521.

12. O'Donovan A, Davies AA, Moggs JG, West SC, Wood RD: XPG endonuclease makes the $3^{\prime}$ incision in human DNA nucleotide excision repair. Nature 1994, 371:432-435.

13. Matsunaga T, Park CH, Bessho T, Mu D, Sancar A: Replication protein A confers structure-specific endonuclease activities to the XPF-ERCC1 and XPG subunits of human DNA repair excision nuclease. J Biol Chem 1996, 271:11047-11050.

14. Bessho T, Sancar A, Thompson LH, Thelen MP: Reconstitution of human excision nuclease with recombinant XPF-ERCC1 complex. J Biol Chem 1997, 272:3833-3837.

15. Shivji MK, Podust VN, Hubscher U, Wood RD: Nucleotide excision repair DNA synthesis by DNA polymerase epsilon in the presence of PCNA, RFC, and RPA. Biochemistry 1995, 34:5011-5017.

16. Wang G, Chuang L, Zhang X, Colton S, Dombkowski A, Reiners J, Diakiw A, $\mathrm{X} U \mathrm{XS}$ : The initiative role of XPC protein in cisplatin DNA damaging treatment-mediated cell cycle regulation. Nucleic Acids Res 2004 32:2231-2240.

17. Araujo SJ, Nigg EA, Wood RD: Strong functional interactions of TFIIH with XPC and XPG in human DNA nucleotide excision repair, without a preassembled repairosome. Mol Cell Biol 2001, 21:2281-2291.

18. Yokoi M, Masutani C, Maekawa T, Sugasawa K, Ohkuma Y, Hanaoka F: The xeroderma pigmentosum group $\mathrm{C}$ protein complex XPC-HR23B plays an important role in the recruitment of transcription factor $\mathrm{IH}$ to damaged DNA. J Biol Chem 2000, 275:9870-9875.

19. Leveillard T, Andera L, Bissonnette N, Schaeffer L, Bracco L, Egly JM, Wasylyk B: Functional interactions between p53 and the TFIIH complex are affected by tumour-associated mutations. EMBO J 1996, 15:1615-1624

20. Kraemer $\mathrm{KH}$, Lee MM, Scotto J: DNA repair protects against cutaneous and internal neoplasia: evidence from xeroderma pigmentosum. Carcinogenesis 1984, 5:511-514.

21. Kraemer $\mathrm{KH}$, Myung ML, Scotto J: Xeroderma pigmentosum. Cutaneous, ocular, and neurologic abnormalities in 830 published cases. Arch Dermatol 1987, 123:241-250.

22. Cheo DL, Burns DK, Meira LB, Houle JF, Friedberg EC: Mutational inactivation of the xeroderma pigmentosum group $C$ gene confers predisposition to 2-acetylaminofluorene-induced liver and lung cancer and to spontaneous testicular cancer in Trp53-/- mice. Cancer Res 1999, 59:771-775.

23. Friedberg EC, Cheo DL, Meira LB, Reis AM: Cancer predisposition in mutant mice defective in the XPC DNA repair gene. Prog Exp Tumor Res $1999,35 \cdot 37-52$

24. Friedberg EC, Bond JP, Burns DK, Cheo DL, Greenblatt MS, Meira LB, Nahari D, Reis AM: Defective nucleotide excision repair in xpc mutant mice and its association with cancer predisposition. Mutation Res 2000, 459:99-108.

25. Meira LB, Reis AM, Cheo DL, Nahari D, Burns DK, Friedberg EC: Cancer predisposition in mutant mice defective in multiple genetic pathways: uncovering important genetic interactions. Mutation Res 2001, 477:51-58.

26. Cheo DL, Friedberg EC: Use of nucleotide excision repair-deficient mice as a model for chemically induced lung cancer. Methods Mol Med 2003, 74:481-491.

27. Hollander MC, Philburn RT, Patterson AD, Velasco-Miguel S, Friedberg EC, Linnoila RI, Fornace AJJ: Deletion of XPC leads to lung tumors in mice and is associated with early events in human lung carcinogenesis. Proc Natl Acad Sci USA 2005, 102:13200-13205.

28. Chen Z, Yang J, Wang G, Song B, Li J, Xu Z: Attenuated expression of xeroderma pigmentosum group $C$ is associated with critical events in human bladder cancer carcinogenesis and progression. Cancer Res 2007 67:4578-4585.

29. Wu YH, Tsai Chang JH, Cheng YW, Wu TC, Chen CY, Lee H: Xeroderma pigmentosum group $\mathrm{C}$ gene expression is predominantly regulated by promoter hypermethylation and contributes to p53 mutation in lung cancers. Oncogene 2007, 26:4761-4773.

30. Thiel G, Lietz M, Hohl M: How mammalian transcriptional repressors work. Eur J Biochem 2004, 271:2855-2862.

31. Ballestar E, Esteller M: Epigenetic gene regulation in cancer. Adv Genet 2008, 61:247-267

32. Vaissière $T$, Sawan Z: Epigenetic interplay between histone modifications and DNA methylation in gene silencing. Mutat Res 2008, 659:40-48.

33. Valeri N, Vannini I, Fanini F, Calore F, Adair B, Fabbri M: Epigenetics, miRNAs, and human cancer: a new chapter in human gene regulation. Mamm Genome 2009, 20:573-580

34. Kurokawa R, Rosenfeld MG, Glass CK: Transcriptional regulation through noncoding RNAs and epigenetic modifications. RNA Biol 2009, 6:233-236.

35. Dupont C, Armant DR, Brenner CA: Epigenetics: defination, mechanisms and clinical perspective. Semin Reprod Med 2009, 27:351-357.

36. Verdone L, Caserta M, Di Maur E: Role of histone acetylation in the control of gene expression. Biochem Cell Biol 2005, 83:344-353.

37. Khan AN, Tomasi TB: Histone deacetylase regulation of immune gene expression in tumor cells. Immunol Res 2008, 40:164-178.

38. Kampranis SC, Tsichlis PN: Histone demethylases and cancer. Adv Cancer Res 2009, 102:103-169.

39. Colton SL, Xu XS, Wang AY, Wang G: The involvement of Ataxiatelangiectasia Mutated protein activation in nucleotide excision repairfacilitated cell survival with cisplatin treatment. J Biol Chem 2006, 281:27117-27125.

40. Lomonaco $\mathrm{SL}, \mathrm{Xu} X \mathrm{X}$, Wang $\mathrm{G}$ : The role of $\mathrm{Bcl}-\mathrm{x}(\mathrm{L})$ protein in nucleotide excision repair-facilitated cell protection against cisplatin-induced apoptosis. DNA \& Cell Biology 2009, 28:285-294.

41. Won J, Yim J, Kim TK: Sp1 and Sp3 recruit histone deacetylase to repress transcription of human telomerase reverse transcriptase (hTERT) promoter in normal human somatic cells. J Biol Chem 2002, 277:38230-38238.

42. Ryu H, Lee J, Olofsson BA, Mwidau A, Dedeoglu A, Escudero M, Flemington E, Azizkhan-Clifford J, Ferrante RJ, Ratan RR: Histone deacetylase inhibitors prevent oxidative neuronal death independent of expanded polyglutamine repeats via an Sp1-dependent pathway. Proc Natl Acad Sci USA 2003, 100:4281-4286.

43. Zhao S, Venkatasubbarao K, Li S, Freeman JW: Requirement of a specific Sp1 site for histone deacetylase-mediated repression of transforming growth factor beta Type II receptor expression in human pancreatic cancer cells. Cancer Res 2003, 63:2624-2630.

44. Yokota T, Matsuzaki Y, Miyazawa K, Zindy F, Roussel MF, Sakai T: Histone deacetylase inhibitors activate INK4d gene through Sp1 site in its promoter. Oncogene 2004, 23:5340-5349.

45. Marinova $Z$, Ren $M$, Wendland JR, Leng $Y$, Liang MH, Yasuda $S$, Leeds $P$, Chuang DM: Valproic acid induces functional heat-shock protein 70 via Class I histone deacetylase inhibition in cortical neurons: a potential role of Sp1 acetylation. J Neurochem 2009, 111:976-987.

46. Mottet D, Pirotte S, Lamour V, Hagedorn M, Javerzat S, Bikfalvi A, Bellahcène $A$, Verdin $E$, Castronovo V: HDAC4 represses p21(WAF1/Cip1) expression in human cancer cells through a Sp1-dependent, p53independent mechanism. Oncogene 2009, 28:243-256. 
47. Song J, Noh JH, Lee JH, Eun JW, Ahn YM, Kim SY, Lee SH, Park WS, Yoo NJ, Lee JY, Nam SW: Increased expression of histone deacetylase 2 is found in human gastric cancer. APMIS 2005, 113:264-268.

48. Ozda H, Teschendorff AE, Ahmed AA, Hyland SJ, Blenkiron C, Bobrow L, Veerakumarasivam A, Burtt G, Subkhankulova T, Arends MJ, Collins VP, Bowtell D, Kouzarides T, Brenton JD, Caldas C: Differential expression of selected histone modifier genes in human solid cancers. BMC Genomics 2006, 7:90.

49. Weichert W, Röske A, Gekeler V, Beckers T, Stephan C, Jung K, Fritzsche FR, Niesporek S, Denkert C, Dietel M, Kristiansen G: Histone deacetylases 1, 2 and 3 are highly expressed in prostate cancer and HDAC2 expression is associated with shorter PSA relapse time after radical prostatectomy. $\mathrm{Br}$ J Cancer 2008, 98:604-610.

50. Fritzsche FR, Weichert W, Röske A, Gekeler V, Beckers T, Stephan C, Jung K, Scholman K, Denkert C, Dietel M, Kristiansen G: Class I histone deacetylases 1, 2 and 3 are highly expressed in renal cell cancer. $B M C$ Cancer 2008, 8:381.

51. Jin KL, Pak JH, Park JY, Choi WH, Lee JY, Kim JH, Nam JH: Expression profile of histone deacetylases 1, 2 and 3 in ovarian cancer tissues. J Gynecol Oncol 2008, 19:185-190.

52. Ashktorab H, Belgrave $K$, Hosseinkhah F, Brim H, Nouraie M, Takkikto M, Hewitt S, Lee EL, Dashwood RH, Smoot D: Global histone H4 acetylation and HDAC2 expression in colon adenoma and carcinoma. Dig Dis Sci 2009, 2(54):2109-2117.

53. Marquard L, Poulsen CB, Gjerdrum LM, de Nully Brown P, Christensen IJ, Jensen PB, Sehested M, Johansen P, Ralfkiaer E: Histone deacetylase 1, 2, 6 and acetylated histone $\mathrm{H} 4$ in B- and T-cell lymphomas. Histopathology 2009, 54:688-698.

54. Halkidou K, Cook S, Leung HY, Neal DE, Robson CN: Nuclear accumulation of histone deacetylase 4 (HDAC4) coincides with the loss of androgen sensitivity in hormone refractory cancer of the prostate. Eur Urol 2004, 45:382-389.

55. Wilson AJ, Byun DS, Nasser S, Murray LB, Ayyanar K, Arango D, Figueroa M, Melnick A, Kao GD, Augenlicht LH, Mariadason JM: HDAC4 promotes growth of colon cancer cells via repression of p21. Mol Biol Cell 2008, 19:4062-4075.

56. Cepeda V, Fuertes MA, Castilla J, Alonso C, Quevedo C, Pérez JM: Biochemical mechanisms of cisplatin cytotoxicity. Anticancer Agents Med Chem 2007, 7:3-28.

57. Stewart DJ: Mechanisms of resistance to cisplatin and carboplatin. Crit Rev Oncol Hematol 2007, 63:12-31.

58. Köberle B, Tomicic MT, Usanova S, Kaina B: Cisplatin resistance: preclinical findings and clinical implications. Biochim Biophys Acta 2010, 1806:172-182.

59. Wu YH, Cheng YW, Chang JT, Wu TC, Chen CY, Lee H: Reduced XPC messenger RNA level may predict a poor outcome of patients with nonsmall cell lung cancer. Cancer 2007, 110:215-223.

doi:10.1186/1756-8722-4-17

Cite this article as: Xu et al:: Histone deacetylases (HDACs) in XPC gene silencing and bladder cancer. Journal of Hematology \& Oncology 2011 4:17.

\section{Submit your next manuscript to BioMed Central and take full advantage of:}

- Convenient online submission

- Thorough peer review

- No space constraints or color figure charges

- Immediate publication on acceptance

- Inclusion in PubMed, CAS, Scopus and Google Scholar

- Research which is freely available for redistribution 